\title{
The Feasibility Study of Smartphone-aided Mobile Learning in Colleges
}

\author{
Jiajun Hong \\ Jiangxi Science and Technology Normal University, Nanchang, 330013, China \\ Hongjiajun11135@163.com
}

Keywords: Feasibility study; Mobile learning; Smart phone

\begin{abstract}
Mobile learning enables college students to obtain information and acquire knowledge through mobile devices anytime and anywhere. This article briefly analyzes the feasibility of conducting Mobile learning in colleges aided by the smart phones. The study shows that the smart phone has been taken as the best mobile learning tool since it is the most popular device with powerful functions, desirable prices and a potential to be connected to college learning, and it is feasible and beneficial to carry out the smartphone-aided mobile learning in colleges.
\end{abstract}

\section{Introduction}

People's life has changed greatly for another time, with the extensive use of Internet technology and mobile communication technology nowadays. People benefit greatly from this new age, the driving power for the development of education. The advancing of the modern education exposes more and more defects in the traditional classes applying the old teaching methods. At the same time, the society has a higher requirement for college grads who seem failed to meet the new requirement of the job market. Mobile learning, a creative way to fix the problems, enables college students to obtain information and acquire knowledge through mobile devices anytime and anywhere. Is mobile learning feasible in colleges? The following is about to analyze the feasibility of conducting smartphone-aided mobile learning in colleges.

\section{Mobile Learning}

Mobile learning, in the past, was conducted in the fields of digital education and remote education. It just appears for a very short period of time and it isn't used widely in our country. Up till now there has not a universal definition, and researchers tend to define it from the perspectives of their own interests. Currently, there exist some different understandings on mobile learning. For example, some researchers think that mobile learning is just a form of distance learning. Some researchers hold that mobile learning is the expansion of E-learning. It shares the same learning contents with E-learning and the difference between the two lies in that for a mobile learning model, people obtain information and acquire knowledge through mobile internet and mobile communication devices. Some researchers explore that from the perspective of cognition and learning. They argue that mobile learning and E-learning and web-based learning share the same features in learning contents and forms, while its mobility and flexibility makes it a new and creative learning style.

To sum up, mobile learning is a new learning model that through mobile leaning devices (such as portable computers, smart phones), learners can obtain the information, resources and services they need at any time and at any place.

According to the previous studies, mobile learning can improve the teaching and learning efficiency for the college students. Facing to the information-based society, the mobile learning is the inevitable trend for the social development. Recently, with the development of wireless mobile devices, the mobile leaning is gaining popularization gradually. At the same time, the development of the international and communicational technology has laid the foundation of promotion of the mobile 
learning. It can effectively improve the deficiency in traditional teaching by the connection of mobile learning and new media technology.

\section{The Feasibility Analysis for the Smartphone-aided Mobile Learning in Colleges}

In most areas in our country, smart phone has been the necessary part of our daily life. It not only realizes people's connection at any time but also surf the internet, take photos and amuse themselves. The new media has brought many conveniences for people's life. With the rapid development of the society, smart phone will definitely be used in college education.

Smart Phone. With the improvement of technology, the use of smart phone, the fifth media, is shown gradually. A smart phone, evolving from a smart phone, has a operation system built inside, with a more powerful computing capability and function. Users can even expand the function of the phone by installing various software and games and some other apps according to their will.

Basic Feature of the Smart Phone. Compared with the traditional media-newspaper, TV, broadcasting, the smart phone has many advantages. It can be summarized as the following respects:

It is small and portable. Recently, smart phones in market are portable and beautiful. It can help people receive information at any time. The communication through smart phone make a breakthrough in time and space. It isn't like newspaper and TV because of their scheduled time. And smart phone can receive information not only in a fixed position but in a moving situation. It can also receive and send emails and text. Now, people wish that they can receive and send information at any time anywhere and broaden the contact ways. Texts, qq, wechat meet the demands of it. It is the personalized communication tool. The transmission mode of smart phone isn't the traditional "one to one" but "one to many" or "many to many". While the former medias transmit the completely same information to all people, smart phone can make a more flexible content to different receivers according to the actual needs. It is economical and practical. With the improvement of the science and technology, the price of smart phones is cheaper and cheaper. Its real-time and practicality can effectively improve the questions in the former teaching activities and it can be the carrier in the development of mobile learning. It is more friendly with a bigger screen and larger capacity, and it is also quicker in computing and processing.

Current Situation of the Use of Smart Phones and Mobile Learning in Colleges. The data from Pew Research Center indicates smart phone is enjoying a more than $50 \%$ penetration in China, which is far above the world average rate and the number is still going to climb higher.

A survey conducts among college students, most of them have used smart phones. Some even have 2 or 3 smart phones. And the results of the survey show that more than $92 \%$ of them own smart phones and more than $82 \%$ think that smart phone is a beneficial tool in terms of communication, cooperation, instruction and getting more information; In the order of using frequency, the intentions of using cell phones are "make calls and text messages"(100\%), "read news"( $89.7 \%)$, "communicate with friends with soft wares"(85\%), "listen to music and watch films"(36\%),"study"(34\%), "play games"(28\%), "read E-novels"(15\%) They hasn't taken full advantage of smart phone.; $87 \%$ of them show an interest in mobile learning, and more than $75 \%$ believe that will help them get more involved with their study.

In the initial stage of its development history, mobile phone is mainly used to communicate. But in recent years, as the technology advances, it isn't just the telephone call. It is not only used for communication, but for mobile learning in colleges and transmission of the words, pictures and videos and so on. Totally, smart phone is familiar to most people as a new media. Now, according to the relative report some scholars have exploited new methods to teach in foreign countries. It has more advantages than internet-based teaching and help teachers send teaching videos, documents and pictures through internet. By this way, it can not only enable students to save money but to have access to and download those resources freely at any time anywhere. What's more, by this way, it can create the effective connection between teachers and students and help students learn more. Also, it can activate the students and broaden the ways of study. 
The Smartphone-aided Mobile Learning Enables Learning Without Time and Space Limits. Nowadays, mobile phones have become essential personal belongs. Smart phones with multiple functions definitely make it convenient for learners to learn at any time and at any place. For example, students can use smart phones to remember English words or do some readings when they are taking buses or subways.

Strengthen the Communication between Teachers and Students. In the teaching process, most teachers carry out teaching by group activities. Different schools need to strengthen the communication between group numbers in order to finish learning tasks. The sharing of information is good for the sharing of knowledge for students. As a tool of mobile communication, smart phone can help students communicate in different places and share the knowledge and breakthrough the limits and achieve the teaching objectives. It also can realize the effective communication between teachers and students. The students can put forward questions and ask for some other kinds of helps after class, which will definitely increase the efficiency of solving the learning problems, develop a good relationship between teachers and students, and add students' interests to their study.

Make Announcements about Teaching in Time. In a typical teaching process, the teacher pushes the announcements and learning materials to students. This process if of low efficiency. Now, with the help of the information technology and smart phones, teachers can inform students of important things by some tools such as texting messages, QQ, WeChat with much more convience. Students have the access to those materials which are necessary for their study and they can prepare for them in advance. During this process, the precious time and the labor are saved. For example, when there is a lecture be holding, a message can be send about the necessary information of time and place to students with smart phones, conveniently and even vividly with pictures to catch students attention.

Learning Function of Smart Phones. Take College English as an example, it was likely to have this picture that college students usually spent much time on English learning and it was common to see students with heavy dictionaries and piles of learning materials. With the help of smart phones and the large amounts of learning apps, English learning has benefited a lot from mobile learning. It is convenient for students' learning at anytime and anyplace. For example, English learners nowadays equip their smart phones with some convenient, powerful and friendly learning apps such as YouDao Dict, CC Talk, to help them remember words and practice their listening and speaking abilities. And they can also form learning groups to help each other to improve their learning efficiency.

Inquiry function of smart phones. With smart phones as the main device connected them to the world, students have access to the sea of information. What they need to do is to inquire, in a right way, and be a student good at searching information. Students nowadays can rapidly inquire by their smart phones and solve problems when they are doing exercises and learning. As a response, the smart phone will provide you with everything you need, the answer to the questions, how something works, how to improve you study, how to prepare for you career, and even how to land a job after graduation.

The Problems of Conducting the Smartphone-aided Mobile Learning in Colleges. In the teaching process in colleges, teachers make full use of new media to improve the efficiency of education system, such as the leaning contents, students' learning methods and the innovation of teaching. The use of smart phone can help to achieve mobile learning out of the classrooms. But it also has some problem in mobile learning in colleges.

The smart phone seems not fully play its role as a learning device. From the development of mobile learning in colleges, the smart phones are used not in study but in amusement. Most messages, pictures and videos in their phones have no connection with study.

It is a financial burden for students sometimes. The mobile terminal, the phone, costs more than the former generation of phones, and students need to pay for their access to the internet. What's more, though many students have smart phones, the powerful device for study, few of them will pay for the learning resources. Most of them don't want to invest in learning.

A huge sea of information make students confused sometimes. There are so many to catch, and they lost themselves. They don't have a correct and mature view on how to deal with those 
information and materials, which increase their anxiety, and the frequent and excess use of the smart phone even has a negative effect on their health.

\section{Conclusion}

Up till now, the smartphone-aided mobile learning has not been adopted widely in China. As a new learning style, mobile learning attracts many scholars into this field and is still in research and exploration. Currently, language learning, especially English learning based on smart phones, has shown great advantages and is attracting more and more educators.

This article mainly focus on the feasibility analysis for the smartphone-aided mobile learning in colleges, and the analysis shows that it is feasible to carry out a smartphone-aided mobile learning in colleges. For it enhances the level of communication between teachers and students, helps learners to receive teaching information in time and be good for students' inquiry and learning about resources.

\section{Acknowledgements}

This study is supported by a project of Jiangxi Provincial association with the No.15wx212.

\section{References}

[1] Liu Yaonan. A Study of Mobil Learning Based on the Smart Phone in Higher Education [J]. China Education information, 2016, 21(05):426-428.

[2] Yang Yaping. The Application of Mobile Learning in University Class in the "Internet + " Background: An Example of Ji'nan University [J].The Science Education Article Collects, 2016, 08(24):13-16.

[3] Wang Chang. An Application Research of Mobile Apps Applied in The Game-based Teaching in Colleges [J]. Journal of Lvliang Education Institute, 2016(01).

[4] Hong, J. J. and Yang, B.H. A Study of The Smartphone-aided College English Mobile Learning Model[J]. Journal of Lanzhou Institute of Education, 2016(11).

[5] Desmond Keegan. (2002). The future of learning: From e-learning to m-learning[EB/OL]. http://learning.ericsson.net/mlearning2/project_one/book.html

[6] Singh, H.(2003). Building Effective Blended Learning Programs. Educational TechnologySaddle Brook Then Englewood Cliffs, 43(6), 51-54. 